\title{
PROCESOS DE RECEPCIÓN Y EFECTOS SOCIO-COGNITIVOS DE PELÍCULAS SOBRE INMIGRACIÓN. EL PAPEL MODERADOR DEL PREJUICIO HACIA INMIGRANTES*
}

\section{RECEPTION PROCESSES AND SOCIO-COGNITIVE EFFECTS OF FEATURES FILMS ON IMMIGRATION. THE MODERATING ROLE OF PREJUDICE TOWARDS IMMIGRANTS}

Juan-José Igartua** \& Francisco Javier Frutos

Resumen: Se presentan los resultados de una investigación sobre el impacto de películas sobre inmigración en las actitudes

* Investigación galardonada con el Primer Premio en la XVI edición del «Premio Santo Padre Rubio S. J. para avances en el conocimiento de la inmigración", convocado por el Instituto Universitario de Estudios sobre Migraciones de la Universidad Pontificia Comillas. El rigor científico y la aproximación metodológica, junto con la oportunidad del tema (la cuestión del prejuicio hacia la inmigración) fueron los aspectos considerados de mayor relevancia a la hora de otorgar el premio (Fallo del Jurado de 12 de enero de 2015). Por otro lado, esta investigación se inscribe dentro del proyecto de investigación titulado "Procesos de recepción y efectos socio-cognitivos de películas sobre inmigración. El papel moderador del prejuicio hacia los inmigrantes", que ha sido dirigido por el Dr. Juan José Igartua Perosanz y financiado por el Programa I: Programa de financiación de grupos de investigación del Vicerrectorado de Investigación y Transferencia de la Universidad de Salamanca.

** Universidad de Salamanca

Facultad de Ciencias Sociales

Observatorio de los Contenidos Audiovisuales (OCA)

Campus Unamuno (Edificio FES)

37007 Salamanca

Email: jigartua@usal.es

Observatorio de los contenidos audiovisuales: www.ocausal.es 
hacia dicho colectivo. Se realizó un estudio cuasi-experimental con 142 estudiantes de Bachillerato, estableciéndose dos condiciones: ver una película que enfatizaba la discriminación y suscitaba reacciones de empatía hacia los inmigrantes (Poniente) o ver una película que enfatizaba el contacto intergrupal positivo (El Próximo Oriente). Un mes antes del visionado de las películas se cumplimentó la escala de racismo moderno. Tras el visionado de las películas se midieron la identificación con los personajes del endogrupo y del exogrupo, la actitud hacia la inmigración y otros procesos de recepción relevantes. El visionado de la película diseñada para estimular empatía hacia los inmigrantes provocó mayor identificación con los personajes del exogrupo, lo que a su vez indujo actitudes más positivas hacia la inmigración, pero únicamente cuando el prejuicio previo era bajo o moderado.

Palabras clave: películas sobre inmigración, prejuicio, racismo moderno, actitudes hacia la inmigración, persuasión narrativa.

Abstract: The results of a research on the impact of films on immigration in attitudes towards immigration are presented. A quasi-experimental study with 142 high school students was carried out, establishing two conditions: watching a movie that emphasized discrimination and empathy reactions towards immigrants (Poniente) or watching a movie that emphasized the positive intergroup contact between ingroup and out-group characters (El Próximo Oriente). A month before viewing the movies participants filled a questionnaire that contained a scale to measure modern racism. Immediately after viewing the movies identification with ingroup and out-group characters, attitude towards immigration and other relevant reception processes were measured. It was observed that the film designed to stimulate empathy towards immigrants provoked greater identification with out-group characters, which in turn induced more positive attitudes towards immigration, but only when modern racism was low or moderate.

Keywords: immigration movies, prejudice, modern racism, attitudes toward immigration, narrative persuasion.

\section{INTRODUCCIÓN}

La investigación que aquí se presenta se vincula con el estudio de las relaciones entre los medios de comunicación y el prejuicio hacia inmigrantes y, de manera particular, con dos áreas de estudio: las 
técnicas para reducir las actitudes de rechazo hacia los inmigrantes y los procesos de persuasión narrativa.

El prejuicio es una actitud negativa o de rechazo hacia un individuo por su pertenencia a un determinado grupo. Desde modelos psico-sociales como la teoría de la identidad social (Tajfel, 1982) se propone que, por defecto, las personas manifiestan un favoritismo endogrupal (la tendencia a favorecer a los miembros del propio grupo frente a las personas que forman parte de otro grupo) y una discriminación exogrupal, y este proceso se basa en el proceso cognitivo de la categorización que sería universal. Ahora bien, el prejuicio también es un fenómeno social ya que: su objeto son los miembros de otro grupo o exogrupo (los inmigrantes, en el presente estudio); las actitudes de prejuicio son compartidas mayoritariamente por los miembros del propio grupo o endogrupo (y así se ven reflejadas en artefactos culturales, como en las representaciones mediáticas: noticias, series de televisión y películas, por ejemplo); y, finalmente, el prejuicio refleja el estado de las relaciones intergrupales en un momento determinado, pudiendo variar en el tiempo y en función de las circunstancias, por lo que constituye un proceso que puede modificarse (Molero, 2007).

Aunque los medios de comunicación han sido en muchas ocasiones parte del problema en el origen y mantenimiento del prejuicio, también pueden ser parte de la solución y utilizarse de manera estratégica para reducir el prejuicio, bien a través de campañas de corte publicitario o a través de experiencias ancladas en la educación para la paz y en la aproximación educación-entretenimiento (Igartua, 2011). En ese sentido, organismos e instituciones de diversa índole han señalado que las películas sobre inmigración podrían y deberían ser utilizadas como herramientes pedagógicas en el contexto de la educación para la paz, o la educación en derechos humanos, para provocar efectos positivos de concienciación, reducción de la percepción de amenza e incremento de la tolerancia hacia los inmigrantes (Arana, 2007). Sin embargo, a pesar de que existe un gran volumen de investigaciones sobre la representación del inmigrante en el cine español, no existe investigación empírica hasta la fecha sobre los procesos de recepción de este tipo de películas. La ausencia de investigación sobre los procesos de recepción e impacto socio-cognitivo de películas sobre inmigración constituye una laguna de conocimiento importante porque se desconoce qué impacto pueden provocar las películas cuando se utilicen en intervenciones educativas. 
El estudio que se presenta se vincula, además, con la investigación sobre persuasión narrativa que constituye un campo en el que se "investiga cómo la información situada dentro de las narraciones puede alterar las percepciones de la realidad" (Dahlstrom, 2010, p. 858). Existen estudios empíricos que han analizado el poder de la ficción audiovisual, de manera específica para el cambio de actitudes y creencias (por ejemplo, Baumert, Hofmann y Blum, 2008; Slater, Rouner y Long, 2006). Este tipo de investigación es pertinente porque no solo permite contrastar la capacidad de las narraciones cinematográficas para influir en las actitudes de las personas, sino porque además se analizan empíricamente los procesos o mecanismos responsables de tal influencia y en qué condiciones cabe esperar un mayor impacto persuasivo y en cuáles una mayor resistencia.

En definitiva, en el presente manuscrito se recogen los principales resultados de un estudio de naturaleza cuasi-experimental que tuvo como primer objetivo: contrastar cómo la exposición a diferentes películas sobre inmigración (con visiones diferenciadas sobre el fenómeno de la inmigración) influye en las actitudes hacia la inmigración. El segundo objetivo del estudio fue analizar el papel del prejuicio previo como variable moderadora que condiciona el impacto de dichas películas. Y, en tercer lugar, se profundizó en el análisis de los mecanismos de la persuasión narrativa y, en particular, el papel mediador de la identificación con los personajes.

\subsection{Cine e inmigración: del análisis de la representación al estudio de los procesos de recepción}

Varios trabajos han puesto de manifiesto que la inmigración, cada vez más, forma parte de las producciones cinematográficas desarrolladas en España (Gordillo, 2006; Iglesias, 2010; Moyano, 2005; Santaolalla, 2005). Existen varios trabajos publicados en los últimos años que han abordado el estudio de la representación de la inmigración y los inmigrantes en la filmografía española (Castiello, 2005; Conte, 2010; Martínez-Carazo, 2010; Zecchi, 2010). Por ejemplo, el trabajo de Castiello (2005) aporta un exhaustivo análisis de las películas que considera más representativas sobre inmigración realizadas en España entre 1990 y 2005. A pesar de la existencia de diversos estudios con análisis detallados sobre las películas sobre inmigración y de las propuestas a favor del cine como una 
herramienta para la educación para la paz y el fomento de actitudes de tolerancia y la reducción del prejuicio, son prácticamente inexistentes las investigaciones nacionales e internacionales sobre los procesos de recepción y efectos socio-cognitivos.

Desde otro ámbito, se ha podido determinar que una de las estrategias más eficaces para reducir el prejuicio es facilitar la interacción o el contacto directo entre personas del endogrupo y exogrupo (Pettigrew y Tropp, 2006). Pero también se ha observado que los efectos positivos del contacto pueden darse aunque éste sea indirecto, vicario o meramente simbólico, y es ahí donde el papel de la ficción audiovisual puede ser determinante (Crisp y Turner, 2009; Park, 2012; Wright, Aron, McLaughlin-Volpe y Ropp, 1997). En este sentido, desde la teoría del contacto parasocial se mantiene que exponerse a través de los medios de comunicación (televisión o cine, por ejemplo) a ejemplos de relaciones interculturales positivas y exitosas entre personajes del endogrupo y personajes del exogrupo constituye una oportunidad de contacto parasocial que refuerza actitudes de aceptación hacia los miembros del exogrupo y modela comportamientos de contacto intergrupal (Schiappa, Gregg y Hewes, 2005).

En el campo de la psicología social, se ha señalado también que una forma eficaz para mejorar las actitudes hacia un grupo estigmatizado (minorías culturales o étnicas, inmigrantes, personas con discapacidad, etc.), reducir la percepción de amenaza y reducir el favoritismo endogrupal es fomentando la empatía con respecto a un miembro que forma parte del exogrupo estigmatizado (Batson, Polycarpou, Harmon-Jones et al., 1997; Finlay y Stephan, 2000). En este sentido, ciertas producciones audiovisuales (como El Color Púrpura, Rain Man, Bwana, por ejemplo), que presentan casos particulares de personas que forman parte de grupos estigmatizados, podrían ser utilizadas para mejorar la imagen de dichos grupos, al permitir que las audiencias empaticen con los personajes que las protagonizan y ello conducir a cambios actitudinales.

En un estudio experimental realizado en Holanda, sobre el impacto de una serie televisiva con un mensaje favorable al contacto multicultural, se observó que la exposición a la serie dramática multicultural (en comparación con el visionado de una serie que actuó como control) reducía la percepción de amenaza intercultural y estimulaba la identificación con los personajes del exogrupo (Müller, 2009). En otro estudio experimental se comprobó que 
la exposición a la película Un día sin mexicanos (con un mensaje positivo hacia la inmigración) reforzaba una actitud favorable hacia la inmigración y las creencias sobre la contribución positiva de la inmigración en la economía de los países de acogida (Igartua, 2010). Finalmente, en un estudio experimental sobre el impacto de una película con un mensaje contrario al racismo (ejercido contra personas afroamericanas en Estados Unidos) se comprobó que el nivel de prejuicio previo (medido con la escala de racismo moderno de McConahay, Hardee y Batts, 1981) influía en la interpretación de la película y en las reacciones ante la misma (Eno y Ewoldsen, 2010). Este último estudio demuestra que a la hora de explicar el impacto de la ficción audiovisual (cinematográfica, en el presente trabajo) es preciso contemplar no sólo cómo se representa el inmigrante en las narraciones de ficción, sino también analizar el papel de las diferencias individuales, como el nivel previo de prejuicio hacia los inmigrantes.

El presente estudio toma en consideración los trabajos sobre racismo moderno, como una variable que puede condicionar los procesos de recepción. El racismo moderno constituye una forma de prejuicio más sutil, indirecta, racionalizada y fría que las viejas formas de prejuicio y se vincula con reacciones ambivalentes hacia las personas de un determinado exogrupo (en nuestro caso, los inmigrantes) (Molero, 2007). Por un lado, la persona que manifiesta alto racismo moderno considera que los inmigrantes ( $u$ otras minorías étnicas) quebrantan las normas y valores de la sociedad de acogida; además, creen que "piden demasiado", piensan que el gobierno o las instituciones dedica excesivos recursos sociales o económicos para proteger a los inmigrantes, que el propio grupo está siendo ignorado o perjudicado y, por ello, se experimenta un cierto resentimiento hacia dichos grupos. Pero, por otro lado, las personas con alto racismo moderno muestran un fuerte rechazo hacia los estereotipos más zafios y hacia la discriminación abierta, y asumen que el racismo es un hecho del pasado (Espelt, 2009). Por todo ello, el racismo moderno se vincula con reacciones de desconfianza y de evitación de contacto hacia las personas del exogrupo, y también con sentimientos de incomodidad, inseguridad, desconfianza y una menor manifestación de sentimientos positivos (Navas, 1998). 


\subsection{Persuasión narrativa y narración audiovisual: procesos y mecanismos}

La influencia de la ficción en las actitudes se ha convertido en los últimos años en un nuevo dominio de investigación denominado persuasión narrativa (Green y Brock, 2000; Igartua, 2007; Slater y Rouner, 2002; Moyer-Gusé, 2008). La evidencia empírica indica que las narraciones de ficción ejercen efectos significativos más allá del puro entretenimiento, la diversión y el impacto afectivo. Se ha constatado que la exposición a contenidos específicos de ficción como relatos escritos (Diekman, McDonald y Gardner, 2000), largometrajes (Baumert et al., 2008), series de televisión (Slater et al., 2006;) o producciones audiovisuales desarrolladas en el campo de la educación-entretenimiento (Moyer-Gusé y Nabi, 2010), ejerce efectos significativos en las actitudes sobre los tópicos abordados en dichas narraciones.

Existe una variedad de modelos que dan cuenta de diferentes aspectos del proceso de persuasión incidental a través de narraciones de ficción, siendo los más representativos: el modelo del transporte narrativo (Green y Brock, 2000), el modelo extendido de probabilidad de elaboración (E-ELM; Slater y Rouner, 2002) y el modelo de procesos paralelos de persuasión incidental (MP3I; Igartua, 2007, 2011). En dichos modelos se considera que la identificación con los personajes juega un papel relevante en los procesos de persuasión narrativa (Dal Cin, Zanna y Fong, 2002; de Graaf, Hoeken, Sanders, Beentjes, 2012). La identificación con los personajes se define como un constructo multidimensional, siendo sus dimensiones básicas la empatía cognitiva (toma de perspectiva), la empatía emocional (vivir las emociones de los personajes) y la sensación de volverse el personaje o asumir temporalmente su identidad y metas (merging) (Cohen, 2001; Igartua y Barrios, 2012; Moyer-Gusé, 2008).

Tanto desde el modelo de transporte narrativo de Green y Brock (2000) como desde el E-ELM de Slater y Rouner (2002), se plantea que cuando las personas se involucran con gran intensidad con un texto de narrativo (sea de ficción o no) toda su capacidad atencional y de procesamiento se centra en el relato con objeto de comprender la trama e implicarse emocionalmente con las peripecias de los personajes. Por ello, en dichas circunstancias el procesamiento crítico se convierte en una respuesta poco probable porque la contra-argumentación es un proceso incompatible con la recepción implicada. 
Por ello, dado que la exposición a narraciones de ficción desactiva por defecto la crítica o contra-argumentación cabe plantear, desde esta perspectiva teórica, que su impacto persuasivo debería ser mayor en personas con una actitud previa contraria al mensaje de la narración. Ello se explicaría porque el mensaje contra-actitudinal actúa bajo el radar de la persona ya que ésta se expone a la narración para buscar diversión o entretenimiento. Por tanto, tomando como referencia ambos modelos teóricos, se deduce que la influencia persuasiva de películas sobre inmigración con un mensaje favorable hacia los inmigrantes se vería facilitada en personas con alto prejuicio previo, dado que la inmersión en la narración y la implicación con sus personajes desactivarían los procesos de contra-argumentación.

Sin embargo, desde el MP3I (Igartua, 2007, 2011) que se basa parcialmente en la teoría del juicio social (Sherif y Hovland, 1961), se plantea que cualquier intento de explicar los efectos de las comunicaciones persuasivas debe comenzar por considerar al sujeto o a la audiencia, es decir, tener en cuenta su posición o actitud previa (y el grado de consolidación de ésta) frente al tema aludido en el mensaje. Desde este planteamiento, para comprender el impacto de la narración de ficción audiovisual habría que tener en cuenta no sólo el mensaje o los argumentos implícitos del mismo (en este caso, la imagen de la inmigración en diferentes películas), sino que es preciso considerar la actitud previa del sujeto y tomarla como punto de partida para poder determinar el impacto persuasivo que se puede alcanzar con un mensaje dado (Dal Cin et al., 2002). Así, lo que determinará el impacto actitudinal por la exposición a un contenido narrativo de ficción, será la distancia percibida (o grado de discrepancia) entre la posición previa del individuo y la posición mantenida en el mensaje. El impacto de una narración de ficción será mayor si se percibe poca o moderada discrepancia o distancia entre el mensaje implícito en la narración y la actitud previa hacia el objeto sobre el que versa el contenido de ficción. En cambio, si existe una alta discrepancia con respecto al mensaje implícito en la narración, el impacto persuasivo será menor.

\subsection{Contexto de la investigación e hipótesis}

El presente estudio, de naturaleza cuasi-experimental, pretende contribuir al esclarecimiento sobre el papel moderador de las acti- 
tudes previas (en este caso, del racismo moderno) en los procesos de recepción de largometrajes sobre inmigración. Además, también se buscaba obtener evidencia sobre los procesos responsables del impacto persuasivo, en concreto, la identificación con los personajes del exogrupo. En la investigación que se presenta participaron estudiantes de bachillerato que fueron distribuidos a dos condiciones experimentales: un primer grupo vio la película Poniente y un segundo grupo vio la película El Próximo Oriente. Un mes antes del visionado de las películas los participantes cumplimentaron un primer cuestionario (que se presentó como un estudio diferente) y en el que se incluyó una medida de prejuicio hacia los inmigrantes (racismo moderno) y otras variables de control. Inmediatamente después de realizarse el visionado de las películas, se cumplimentó un segundo cuestionario que evaluaba diferentes criterios relacionados con los procesos de recepción y la variable dependiente del estudio (actitud hacia la inmigración).

La primera de las hipótesis se relaciona con el impacto del visionado de las películas en la actitud hacia la inmigración. Se planteó que la película Poniente, al evidenciar situaciones de discriminación hacia los inmigrantes, mostrar situaciones de sufrimiento que pueden inducir empatía en el espectador medio y al suponer una denuncia del racismo, induciría una actitud positiva hacia la inmigración.

H1. El visionado de la película Poniente (en comparación con el visionado de la película El Próximo Oriente) inducirá una actitud positiva hacia la inmigración.

Una de las dimensiones fundamentales de la identificación con los personajes es la empatía. Y la empatía se considera una de las técnicas principales para reducir el prejuicio (Batson et al., 1997). De este modo, se puede suponer que una película que muestre una situación de conflicto entre personajes del endogrupo y del exogrupo, y de discriminación hacia los inmigrantes, denunciando al mismo tiempo la xenofobia y el racismo, y en comparación con una película que carezca de dichos elementos, provocará una mayor reacción empática hacia los inmigrantes que se manifestará en una elevada identificación con los personajes inmigrantes (exogrupo) de la película.

H2. La película Poniente inducirá mayor identificación con los personajes inmigrantes que la película El próximo Oriente. 
Las investigaciones previas han demostrado que las personas más prejuiciosas muestran más rechazo hacia la inmigración. Es lógico pensar que este efecto también se manifieste en una situación de contacto intergrupal mediático o parasocial, como lo es visionar una película en la que los inmigrantes tienen un papel protagónico. De este modo, es muy probable que las personas con un alto nivel de prejuicio previo experimenten una menor identificación empática con los personajes inmigrantes. De forma complementaria, cabe esperar que la película con un mensaje de denuncia del racismo inducirá mayor identificación con los personajes inmigrantes que la película que no aborde este tema, pero dicho efecto será más pronunciado entre las personas con un nivel bajo o moderado de prejuicio previo hacia los inmigrantes.

H3a. Se observará una relación negativa entre el nivel de prejuicio previo hacia los inmigrantes y el nivel de identificación con los personajes inmigrantes de las películas visionadas.

H3b. El efecto del visionado de la película Poniente en la identificación con los personajes inmigrantes protagonistas de la misma estará moderado por el grado de racismo moderno de los participantes. De este modo, los participantes expuestos experimentalmente a dicha película (en comparación con los que vean El Próximo Oriente) manifestarán mayor identificación con los personajes inmigrantes pero exclusivamente cuando el nivel de prejuicio previo sea bajo o moderado.

Los modelos de persuasión narrativa consideran que la identificación con los personajes constituye un proceso mediador relevante del impacto de las narraciones de ficción en las actitudes y creencias. En el contexto de la investigación sobre reducción del prejuicio a través de contenidos mediáticos, Park (2012), partiendo de la hipótesis del contacto parasocial (Schiappa et al., 2005), plantea tres procesos relevantes en el contacto mediático intergrupal: la interacción parasocial con los personajes del exogrupo, la identificación con los personajes del endogrupo que interactúan en la ficción con personajes del exogrupo y la interacción parasocial con un personaje del endogrupo que interactúa en la ficción con un personaje del exogrupo. Sin embargo, no ha considerado el papel de la identificación con los personajes del exogrupo como un posible mediador, a pesar de que se ha considerado que la 
empatía (un componente central en el concepto de identificación con los personajes) constituye una variable mediadora relevante (Batson et al., 1997). En este sentido, Müller (2009) ha observado que la identificación con los personajes del exogrupo (y no la identificación con los personajes del endogrupo) se asociaba a una menor ansiedad intergrupal y a una actitud más positiva hacia los inmigrantes. Por ello, cabe plantearse que dicho proceso mediador tenga lugar también en el presente estudio. Ahora bien, tomando como referencial el modelo MP3I, se considera que un mensaje resultará persuasivo si es moderadamente discrepante con la actitud previa de los individuos. De este modo, cabe esperar que el proceso mediador hipotetizado (a través de la identificación con los personajes inmigrantes) solo se manifieste cuando el nivel de prejuicio previo hacia los inmigrantes sea bajo o moderado.

H4. El visionado de la película Poniente (en comparación con el visionado de la película El Próximo Oriente) inducirá una alta identificación con los personajes inmigrantes protagonistas de la película, lo que a su vez se asociará a una actitud más positiva hacia la inmigración. Sin embargo, y en consonancia con un modelo de mediación moderada (Hayes, 2013), dicho proceso mediador solo se manifestará entre las personas con bajo o moderado prejuicio previo hacia los inmigrantes (Figura 1).

FIGURA 1

MODELO DE MEDIACIÓN MODERADA

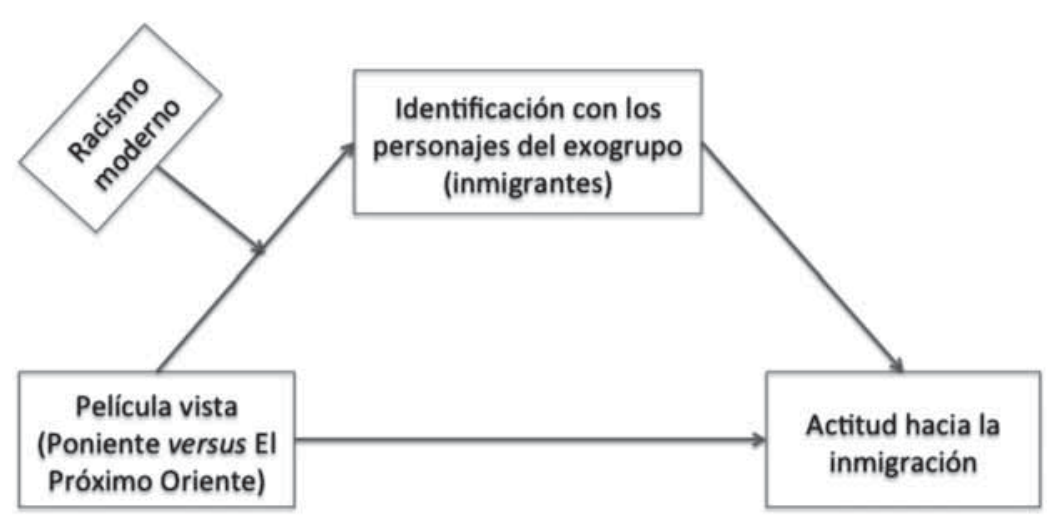




\section{MÉTODO}

\subsection{Participantes}

En la investigación participaron 142 estudiantes de primer curso de Bachillerato, de nacionalidad española, pertenecientes a cuatro Institutos de Educación Secundaria de la ciudad de Salamanca, con los que se había firmado previamente un acuerdo de colaboración. El 50\% de los participantes eran hombres y el 50\% mujeres y la media de edad era de 16.86 años $(D T=1.02$, rango: 16 a 20 años, siendo el $92.3 \%$ entre 16 y 18 años).

\subsection{Diseño y procedimiento}

El estudio tiene una naturaleza cuasi-experimental y se utilizó un diseño de dos grupos con solo medida post-test (sobre las características de este tipo de diseño véase, Igartua, 2006) siendo la variable independiente la película visionada (Poniente o El Próximo Oriente) ${ }^{1}$. Dada la naturaleza de los participantes (estudiantes de Bachillerato pertenecientes a cuatro institutos diferentes) no se pudo realizar una distribución aleatoria de los participantes a los dos tratamientos experimentales (la película visionada), sino distribuir aleatoriamente dos institutos a cada condición, lo que determina que la investigación tenga una naturaleza cuasi-experimental. Debido a la ausencia de un proceso de asignación aleatoria de los individuos a los tratamientos, este tipo de investigación presenta más amenazas a la validez interna que las investigaciones experimentales (Campbel y Stanley, 1973). Para hacer frente a dichas amenazas y, en particular, la posibilidad de que existan diferencias significativas entre los participantes asignados a los diferentes tratamientos antes de que se produzca la intervención, se optó por medir en un cuestionario pre-test variables relevantes como el auto-posicionamiento político,

1 Con objeto de disponer de una medida de comparación en la principal variable dependiente del estudio (la actitud hacia la inmigración), y dado que se utilizó un diseño de dos grupos con solo medida post-test, se obtuvieron datos de dos institutos más (también de la ciudad de Salamanca) que participaron en calidad de grupo control. Estos participantes $(N=88)$ únicamente cumplimentaron un cuestionario con las variables dependientes y de control, y no fueron expuestos a ninguna película. 
el nivel de prejuicio previo hacia inmigrantes, el nivel de contacto con inmigrantes en contextos interpersonales y la percepción de la inmigración como problema para el país. La investigación previa ha contrastado que dichas variables se vinculan con las actitudes hacia la inmigración (Cea D’Ancona, 2004).

La investigación se desarrolló en dos fases. En un primer momento, se administró un cuestionario pre-test en el que se evaluaron los siguientes aspectos: la percepción de problemas sociales, el racismo moderno hacia los inmigrantes, el nivel de contacto con inmigrantes, el auto-posicionamiento político y los datos socio-demográficos. Este cuestionario se aplicó en los cuatro institutos considerados en la misma semana del mes de febrero de 2014. Cuatro semanas después de administrar el cuestionario pre-test (marzo de 2014), se acudió de nuevo a los centros y se realizó la intervención con las películas. Los participantes visionaron en el aula una versión editada de cada película seleccionada (67 personas vieron la película El Próximo Oriente y 75 Poniente). Inmediatamente después de efectuar el visionado los participantes cumplimentaron el cuestionario post-test, diseñado para evaluar los procesos de recepción, la variable dependiente (actitud hacia la inmigración) y datos socio-demográficos como el país de nacimiento (de este modo, se pudieron eliminar los cuestionarios de los participantes de origen extranjero).

\subsection{Descripción de las películas y estudio piloto}

Se utilizaron dos películas sobre inmigración: Poniente (dirigida por Chus Gutiérrez en 2002) y El Próximo Oriente (dirigida por Fernando Colomo en 2006). Las dos películas mencionadas fueron seleccionadas porque presentan dos visiones diferentes del fenómeno de la inmigración. Tomando como referencia las investigaciones sobre el papel de la empatía e identificación en la reducción del prejuicio (Batson et al., 1997; Müller, 2009), se consideró que una película con potencial para reducir el prejuicio hacia los inmigrantes debería provocar la empatía-identificación con los miembros del exogrupo (inmigrantes). Poniente fue la película considerada como más apropiada para cumplir dicho requisito. Martinez-Carazo (2010) apunta que películas como Poniente permiten hacer visible al inmigrante, abren un espacio para la crítica, denunciando el racismo, los estereotipos raciales y culturales, y proponen una reflexión sobre el in- 
migrante, activando la empatía en el espectador. Como contrapunto, se utilizó la película El Próximo Oriente, en la cual se muestran varios ejemplos positivos de relaciones íntimas de pareja entre ciudadanos españoles con inmigrantes asiáticos que mantienen un credo musulmán. Conte (2010) advierte que dicha película (que desarrolla una historia de amor entre un español y una inmigrante musulmana) constituye una "celebración" de la multiculturalidad y del mestizaje.

Dada las limitaciones temporales para realizar el trabajo de campo en los institutos contactados y, por otro lado, con el fin de enfatizar el mensaje de cada película de manera más eficiente, se llevó a cabo un proceso de edición de las películas (inicialmente ambas contaban con una duración en torno a los 90 minutos). De este modo, se crearon versiones de una duración aproximada de 45 minutos, respetando la línea argumental del guion y sin que la historia se viese mermada en ninguno de sus aspectos. Así, en el caso de Poniente se creó una versión de la película con una duración de 47 minutos que enfatizaba las situaciones de conflicto entre los personajes autóctonos (endogrupo) y los inmigrantes (exogrupo) y hacía patente el sufrimiento de los inmigrantes por su situación. Por otro lado, en el caso de El Próximo Oriente se creó una versión con una duración de 46 minutos, que enfatizaba las relaciones de contacto íntimas y positivas entre personajes del endogrupo y del exogrupo.

Se realizó un estudio piloto en el que participaron 45 estudiantes de comunicación audiovisual (68.9\% mujeres y media de edad de 20.51 años). Los participantes del estudio piloto fueron distribuidos en dos grupos y en cada grupo se visionó una película diferente, en el contexto de las clases prácticas de una asignatura del citado grado. Después de efectuar el visionado cumplimentaron un breve cuestionario en el que se preguntaba en qué medida consideraban que una serie de afirmaciones se aplicaban a cada película (por ejemplo: "aunque muestran algunas situaciones de conflicto entre inmigrantes y españoles, el espectador medio sentiría empatía hacia los inmigrantes", "muestra una visión positiva del contacto intercultural, es decir, del contacto entre personas que pertenecen a diferentes culturas"). Los resultados del estudio piloto demostraron que cada película, tal como se esperaba, enfatizaba una visión diferente de la inmigración. La idea del contacto intercultural positivo estaba más presente en la película El Próximo Oriente que en la película Poniente. En cambio, la película Poniente presentaba un mensaje que reforzaba la empatía hacia los inmigrantes y la denuncia del racismo, en mayor medida que El Próximo Oriente. 


\subsection{Instrumentos y variables}

1.- Percepción de la importancia de varios asuntos como problemas del país. Se utilizó para medir, en realidad, la "percepción de la inmigración como problema para el país". Dicha escala se incluía en el cuestionario pre-test y en ella se preguntaba: en qué medida (desde 0 "nada importante", hasta 10 "muy importante) se consideraba que los asuntos que se mostraban en un listado (entre ellos, la inmigración) eran problemas importantes para el país.

2.- Prejuicio hacia los inmigrantes. Se evaluó con la escala de racismo moderno de McConahay et al. (1981), traducida por Navas (1998). Dicha escala se incluía en el cuestionario pre-test para evaluar el nivel de prejuicio hacia los inmigrantes con anterioridad a la exposición a la película (ejemplo de ítem: "en los últimos años, los inmigrantes han conseguido económicamente más de lo que merecen", desde 1 "totalmente en desacuerdo" hasta 7 "totalmente de acuerdo"; $\alpha=.89$ ).

3.- Nivel de contacto con inmigrantes. Se preguntó a cada participante (en el cuestionario pre-test) si mantenía, o había mantenido en el pasado $(1=$ sí, $0=$ no), algún tipo de relación familiar, de amistad, de pareja, de trabajo, de estudios o de vecindad con inmigrantes (Cea D’Ancona, 2004). Se creó un índice de contacto personal con inmigrantes a partir de la suma simple de las seis variables dicotómicas consideradas.

4.- Auto-posicionamiento político. Pregunta incluida en el cuestionario pre-test: "cuando se habla de política se utilizan normalmente las expresiones "izquierda" y "derecha". Teniendo en cuenta la siguiente escala, ¿qué número representaría mejor tu posición política?" (donde 1 = izquierda hasta $10=$ derecha).

5.- Emociones sentidas durante el visionado de la película. Se utilizó la escala de emociones positivas y negativas de Fredrickson (adaptada al español por Páez, Bobowik, Carrera y Bosco, 2012). Dicha escala se incluía en el cuestionario post-test. Se preguntaba a los participantes: “¿cómo te has sentido viendo la película? Piensa en las diferentes cosas que han pasado a lo largo de la película que acabas de ver y, usando la escala de 0 (nada) hasta 4 (mucho), indica cuánto has experimentado los siguientes sentimientos". La escala está formada por 20 ítems: diez sobre emociones positivas (ejemplo: diversión o humor; $\alpha=.86$ ) y otros diez de emociones negativas (ejemplo: enojo o ira; $\alpha=.87$ ). 
6.- Apreciación de la película. Se utilizó la escala creada por Oliver y Bartsch (2010), compuesta por 12 ítems (con un formato tipo Likert de 7 puntos, desde 1 "totalmente en desacuerdo" hasta 7 "totalmente de acuerdo") y diseñada para medir cuatro dimensiones: diversión (ejemplo: "me ha resultado divertido ver la película"; $\alpha=.84$ ), impresión duradera (ejemplo: "esta película se me quedará grabada durante mucho tiempo"; $\alpha=.81$ ), conmovedora, hace pensar (ejemplo: "considero que esta película tiene un significado profundo"; $\alpha=.84$ ) y suspense (ejemplo: "la película te hace tener el corazón en un puño"; $\alpha=.76)$.

7.- Identificación con los personajes protagonistas. Se evaluó con una escala formada por 11 ítems, cuya fiabilidad y validez estructural había sido contrastada en un estudio previo (Igartua y Barrios, 2012). El instrumento está compuesto por 11 ítems, diseñados para medir de manera retrospectiva $(1$ = nada, hasta 5 = mucho) la identificación con un personaje concreto (ejemplo de ítem: "he tenido la impresión de vivir realmente yo mismo la historia de X").

Se analizó la identificación con dos personajes del exogrupo (inmigrantes) y con dos personajes del endogrupo (autóctonos). Para facilitar la tarea, en el cuestionario se incluyó una foto de los personajes. Con respecto a la película Poniente, los personajes del endogrupo fueron Curro (un español que mantiene relaciones de amistad con algunos de los inmigrantes) y Lucía (una joven española, propietaria de varias hectáreas de invernaderos que empatiza con sus trabajadores extranjeros). Por otro lado, los personajes del exogrupo fueron Abdembi (un bereber que trabaja en los invernaderos locales y pretende cambiar, de forma pacífica, las precarias condiciones laborales que le son impuestas a él y a sus compañeros inmigrantes) y Saïd (un joven marroquí, también trabajador de los invernaderos, que se rebela contra la discriminación). En cuanto a la película $E l$ Próximo Oriente, los personajes del endogrupo fueron Caín (un joven bonachón que vive a la sombra de la exitosa vida de su hermano y que decide hacerse cargo de la amante embarazada de éste, de la que acaba enamorándose) y Milagros (una carnicera que entabla una relación amorosa con un hombre de religión islámica). Finalmente, los personajes del exogrupo fueron Aisha (la joven inmigrante a la que el hermano de Caín deja embarazada y con la que este último se casa) y Shakir (el padre de Aisha que acabará aceptando a Caín como miembro de su familia). 
A partir de la aplicación de la escala de identificación para dos personajes protagonistas del endogrupo y otros dos perteneciente al exogrupo, y siguiendo el procedimiento utilizado por Müller (2009) y Moyer-Gusé y Nabi (2010), se crearon dos índices de identificación: identificación con los personajes del endogrupo $(\alpha=.92$ en la película El Próximo Oriente y $\alpha=.94$ en la película Poniente) e identificación con los personajes del exogrupo $(\alpha=.92$ en la película El Próximo Oriente y $\alpha=.96$ en la película Poniente).

8.- Actitud hacia la inmigración. La variable dependiente del estudio se evaluó mediante una escala de un solo ítem, utilizada habitualmente en las encuestas del CIS (Cea D'Ancona, 2004). Se preguntó a los participantes lo siguiente: “como sabes, todos los países desarrollados reciben inmigrantes. ¿Crees que, en términos generales, la inmigración es más bien positiva o más bien negativa para España?" (desde 0 = muy negativa, hasta $10=$ muy positiva).

\section{RESULTADOS}

\subsection{Equivalencia de los grupos experimentales}

Dada la naturaleza cuasi-experimental del estudio, fue prioritario contrastar si los dos grupos experimentales diferían en variables relevantes. Los resultados mostraron que no existían diferencias significativas en ninguna de las cuatro variables consideradas, auto-posicionamiento político $(t(137)=-0.62, p=.532)$, el nivel de prejuicio previo evaluado con la escala de racismo moderno $(t(137)$ $=1.27, p=.206$ ), la percepción de la inmigración como problema para el país $(t(137)=1.39, p=.166)$ y en nivel de contacto personal con inmigrantes $(t(137)=1.40, p=.162)$, lo que significa que ambos grupos eran equivalentes.

\subsection{Impacto del visionado de las películas en los procesos de recepción}

Las dos películas utilizadas como herramientas de intervención audiovisual para reducir el prejuicio diferían en la imagen que se ofrecía de la inmigración, pero también en el acercamiento narrativo. Por tanto, antes de analizar el impacto actitudinal asociado al visiona- 
do de las películas era necesario contrastar el impacto en los procesos de recepción, para comprobar si se habían obtenido las diferencias que cabía esperar, lo que constituiría una garantía de que los participantes se involucraron durante el visionado de dichas películas.

TABLA 1

IMPACTO DEL VISIONADO DE LAS PELÍCULAS EN LOS PROCESOS DE RECEPCIÓN (PRUEBA T DE STUDENT)

\begin{tabular}{|c|c|c|c|c|c|}
\hline \multirow{2}{*}{ Procesos de recepción } & \multicolumn{2}{|c|}{ Condición (película) } & \multirow[b]{2}{*}{$\boldsymbol{t}$} & \multirow[b]{2}{*}{ gl } & \multirow[b]{2}{*}{$p$} \\
\hline & $\begin{array}{c}\text { El Próximo } \\
\text { Oriente }\end{array}$ & Poniente & & & \\
\hline - Emociones positivas & $1.61(0.82)$ & $1.02(0.60)$ & 4.69 & 109.64 & .000 \\
\hline - Emociones negativas & $0.50(0.56)$ & $1.28(0.76)$ & -6.64 & 125.82 & .000 \\
\hline - Es una película divertida & $4.16(1.61)$ & $3.24(1.31)$ & 3.69 & 138 & .000 \\
\hline - Esta película hace pensar & $4.29(1.65)$ & $5.33(1.20)$ & -4.14 & 113.95 & .000 \\
\hline - Esta película deja una impresión duradera & $3.15(1.34)$ & $3.74(1.44)$ & -2.47 & 133 & .015 \\
\hline - Esta película genera suspense & $3.01(1.39)$ & $3.70(1.29)$ & -3.02 & 137 & .003 \\
\hline N & 67 & 75 & & & \\
\hline
\end{tabular}

Nota.- Rango de puntuaciones: emociones positivas y negativas ( $0=$ bajo, $4=$ alto); apreciación: es una película divertida, hace pensar, induce una impresión duradera y genera suspense ( $1=$ totalmente en desacuerdo, 7 = totalmente de acuerdo).

Los resultados indican que existían diferencias estadísticamente significativas en los procesos de recepción en función de la película vista (Tabla 1). Tal como cabía esperar, la película El Próximo Oriente era juzgada como más divertida e inducía más emociones positivas que Poniente. En cambio, Poniente, que presenta un final dramático, indujo la vivencia de emociones negativas durante su visionado, y se consideró que "hacía pensar", "generaba una impresión profunda” y provocaba suspense, en mayor medida que El Próximo Oriente.

\subsection{Impacto del visionado de las películas en la actitud hacia la inmigración}

La hipótesis 1 planteaba que el visionado de la película Poniente induciría una actitud más positiva hacia la inmigración que el visio- 
nado de la película El Próximo Oriente. Mediante la prueba t de Student se comprobó que, efectivamente, los participantes que vieron la película Poniente manifestaron una actitud más positiva hacia la inmigración $(M=5.60, D T=2.08)$ que los participantes que vieron la película "El Próximo Oriente" $(M=4.82, D T=2.34 ; t(140)=-2.10$, $p<.038, r=.17$ ).

El resultado se vio refrendado al realizar un análisis de varianza (Figura 2) y comparar las medias de los dos grupos tratamiento con la media obtenida en el grupo control $(N=88)$. Se observaron diferencias estadísticamente significativas $(F(2,226)=5.75, p<.004$, $\eta_{\mathrm{p}}{ }^{2}=.048$ ), pero en particular al comparar (prueba post hoc Scheffe) la media del grupo expuesto a la película Poniente con la media obtenida por el grupo control $(p<.004)$. No se observaron diferencias estadísticamente significativas entre el grupo control y el grupo expuesto experimentalmente a la película El Próximo Oriente $(p=.590)$.

\section{FIGURA 2}

IMPACTO DEL VISIONADO DE LAS PELÍCULAS EN LA ACTITUD HACIA LA INMIGRACIÓN (ANÁLISIS DE VARIANZA)

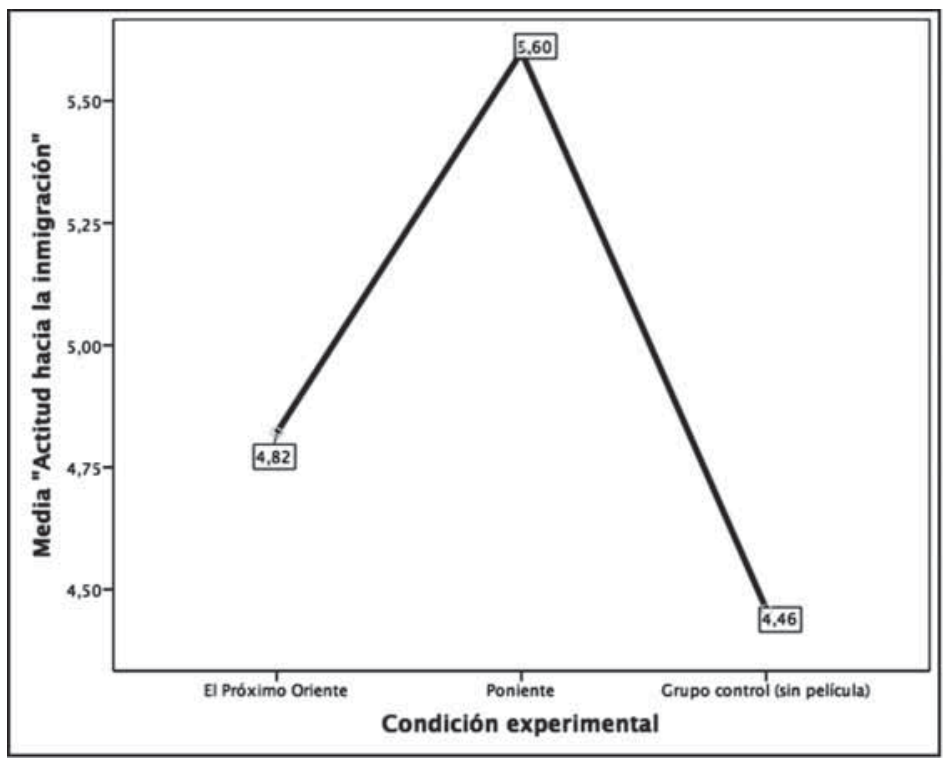




\subsection{El papel moderador del racismo moderno en la identificación con los personajes del exogrupo}

La hipótesis 2 planteaba que la película Poniente induciría una mayor identificación con los personajes del exogrupo (inmigrantes) que la película El Próximo Oriente. Los resultados confirmaron dicha hipótesis ya que se observó una mayor identificación con los personajes del exogrupo entre las personas que habían visto la película Poniente $(M=2.79, D T=0.91)$ que entre los participantes que vieron la película El Próximo Oriente $(M=2.24, D T=0.68 ; t(125.33)=-3.87, p<.001)$.

La hipótesis 3a planteaba que existiría una relación negativa entre el nivel de prejuicio previo hacia los inmigrantes y el nivel de identificación con los personajes inmigrantes de las películas visionadas. Mientras que la hipótesis 3 b predecía que el efecto del visionado de la película Poniente en la identificación con los personajes inmigrantes protagonistas de la misma estaría moderado por el grado de racismo moderno de los participantes. Para contrastar ambas hipótesis se utilizó la macro PROCESS (modelo 1) desarrollada por Hayes (2013), que se basa en el análisis de regresión lineal múltiple (moderated multiple regression). Dicha técnica ha sido considerada la opción más adecuada para analizar la interacción entre una variable independiente experimental (codificada como variable dummy, $0.5=$ Poniente y $-0.5=$ El Próximo Oriente) y una variable independiente continua (la puntuación obtenida en la escala de racismo moderno), ya que permite delimitar las "regiones de significatividad estadística" (mediante la técnica Johnson-Neyman) en las cuales se observa de manera específica el efecto de la variable independiente dicotómica sobre la variable dependiente en los distintos valores de la variable moderadora (Hayes y Matthes, 2009).

Los resultados del análisis mostraron que, de acuerdo con la hipótesis 3a, existía una relación negativa entre el racismo moderno de los participantes y el grado de identificación con los personajes del exogrupo $(B=-.20, p<.001)$. Además, confirmando la hipótesis $3 \mathrm{~b}$, se observó también un efecto de interacción significativo entre la condición experimental (ver Poniente versus El Próximo Oriente) y el nivel de racismo moderno en la identificación con los personajes del exogrupo $(B=-.22, p<.052)$. De este modo, se comprobó que la exposición a la película Poniente indujo una mayor identificación con los personajes inmigrantes (en comparación con ver El Próximo Oriente) cuando el nivel de prejuicio previo era bajo $(B=.76, p<.001)$ o moderado $(B=.48$, $p<.001)$, pero no cuando el nivel de prejuicio era alto $(B=.21, p=.286)$. 


\section{TABLA 2}

\section{ANÁLISIS DEL EFECTO MODERADOR DEL RACISMO MODERNO EN LA RELACIÓN ENTRE EL VISIONADO DE LAS PELÍCULAS Y LA IDENTIFICACIÓN CON LOS PERSONAJES DEL EXOGRUPO (MODELO DE REGRESIÓN MÚLTIPLE MODERADA CON PROCESS)}

\begin{tabular}{|lcccc|}
\hline \multicolumn{1}{|c}{ Variables predictoras } & $\mathrm{B}$ & $\mathrm{SE} \mathrm{B}$ & $\mathrm{t}$ & $\mathrm{p}$ \\
\hline - Constante & 3.12 & .18 & 16.53 & .000 \\
- Racismo moderno (RM) & -.20 & .05 & -3.58 & .000 \\
- Película & 1.16 & .35 & 3.09 & .002 \\
- Interacción "película x RM" & -.22 & .11 & -1.96 & .052 \\
\hline Efecto condicional del visionado de las películas sobre la variable dependiente (identificación con los \\
personajes del exogrupo) en diferentes valores de RM & \multicolumn{3}{c}{} \\
\hline - Bajo RM (-1 DT de la media: 1.81) & .76 & .20 & 3.78 & .000 \\
- Medio RM (3.05) & .48 & .14 & 3.44 & .000 \\
- Alto RM (+ 1 DT de la media: 4.29) & .21 & .19 & 1.06 & .286 \\
\hline
\end{tabular}

Nota.- La variable "película" (visionada) se recodificó como variable dummy asignando el valor 0.5 a haber visto "Poniente" y -0.5 a haber visto "El Próximo Oriente", siguiendo las recomendaciones de Hayes (2013). La variable racismo moderno presenta un rango de puntuaciones desde 1 "bajo", hasta 7 "alto". En la tabla se incluyen los coeficientes B, que son coeficientes de regresión no estandarizados.

Mediante la técnica Johnson-Neyman se calculó el valor crítico en la variable moderadora (racismo moderno) a partir del cual el efecto del visionado de la película Poniente sobre la identificación con los personajes del exogrupo dejaba de ser estadísticamente significativo. Dicho valor era 3.79, en una escala con un rango teórico de 1 a 7 , lo que constituye un valor ligeramente inferior al punto medio teórico de la escala (4), pero ligeramente superior a la media global de los participantes $(M=3.09, D T=1.28)$. El $26.4 \%$ de los participantes en el estudio tuvieron una puntuación superior a dicho valor en la escala de racismo moderno. Lo que significa que para dichos individuos el visionado de la película Poniente no indujo una mayor identificación con los personajes del exogrupo, en comparación con el visionado de la película El Próximo Oriente. En cambio, para la gran mayoría de los participantes (73.6\%), aquellos que mostraron puntuaciones bajas o moderadas en racismo moderno, Poniente sí indujo mayor identificación con los personajes del exogrupo que El Próximo Oriente (Figura 3). 
FigURA 3

EFECTO MODERADOR DEL RACISMO MODERNO EN LA RELACIÓN ENTRE EL VISIONADO DE LAS PELÍCULAS Y LA IDENTIFICACIÓN CON LOS PERSONAJES DEL EXOGRUPO (DIFERENCIA DE MEDIAS)

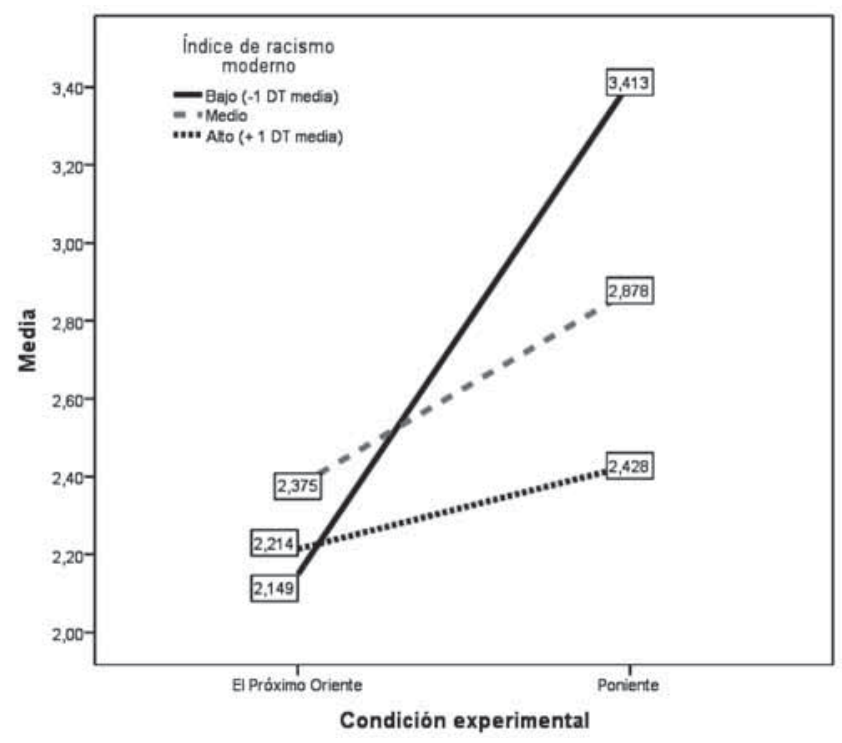

\subsection{Análisis mediacional. Contraste del modelo de mediación moderada}

La hipótesis 4 planteaba un modelo de mediación moderada para tratar de comprender el papel de la identificación con los personajes del exogrupo como variable mediadora del impacto del visionado de las películas en la actitud hacia la inmigración, pero teniendo en cuenta también el papel del racismo moderno como variable moderadora. Para contrastar dicha hipótesis se utilizó la macro PROCESS (modelo 7) para SPSS desarrollada por Hayes (2013). Dicha macro permite contrastar diferentes modelos mediacionales a partir de la técnica de bootstrapping (Hayes, 2009). Este procedimiento, aplicando al modelo 7 , permite calcular los efectos indirectos condicionales, es decir, el efecto de una variable independiente (película visionada) sobre una variable dependiente (actitud hacia la inmigración), a 
través de una variable mediadora (identificación con los personajes del exogrupo) y para diferentes niveles de una variable moderadora (racismo moderno). En la presente investigación los efectos indirectos condicionales se calcularon utilizando 10.000 muestras de bootstrapping, generando intervalos de confianza del tipo bias-corrected boostrap. En este contexto, se considera que un efecto indirecto es estadísticamente significativo si el intervalo de confianza establecido (IC al 95\%) no incluye el valor 0 . Si el valor 0 está incluido en dicho intervalo de confianza no se puede rechazar la hipótesis nula que plantea que el efecto indirecto es igual a 0 , es decir, que no existe asociación entre las variables implicadas (Hayes, 2013).

TABLA 3

ANÁLISIS DE LA MEDIACIÓN MODERADA (PROCESS, MODELO 7)

\begin{tabular}{|c|c|c|c|c|}
\hline \multirow[b]{2}{*}{ Variables predictoras } & \multicolumn{4}{|c|}{$\begin{array}{l}\text { Modelo de variable mediadora } \\
\text { (Identificación con los personajes del exogrupo) }\end{array}$} \\
\hline & B & $S E$ & $t$ & $p$ \\
\hline Constante & 3.12 & .18 & 16.53 & .000 \\
\hline Película & 1.16 & .37 & 3.09 & .002 \\
\hline Racismo moderno (RM) & -.20 & .05 & -3.58 & .000 \\
\hline \multirow[t]{2}{*}{ Interacción "película x RM" } & -.22 & .11 & -1.96 & .052 \\
\hline & \multicolumn{4}{|c|}{$\begin{array}{l}\text { Modelo de variable dependiente } \\
\text { (Actitud hacia la inmigración) }\end{array}$} \\
\hline Variables predictoras & B & $S E$ & $t$ & $p$ \\
\hline Constante & 3.31 & .59 & 5.58 & .000 \\
\hline Identificación con los personajes del exogrupo & .77 & .22 & 3.44 & .000 \\
\hline \multirow[t]{2}{*}{ Película (efecto directo) } & .39 & .38 & 1.01 & .313 \\
\hline & \multicolumn{4}{|c|}{ Efectos indirectos condicionales } \\
\hline Mediador & $\begin{array}{c}\text { Variable } \\
\text { moderadora }\end{array}$ & $B$ & $S E$ & $\begin{array}{c}\text { Boot 95\% } \\
\text { IC }\end{array}$ \\
\hline Identificación con los personajes del exogrupo & RM bajo (1.81) & .59 & .24 & {$[.20,1.16]$} \\
\hline Identificación con los personajes del exogrupo & RM medio (3.05) & .37 & .16 & {$[.12, .78]$} \\
\hline Identificación con los personajes del exogrupo & RM alto (4.29) & .16 & 17 & {$[-.12, .60]$} \\
\hline
\end{tabular}

Nota.- La variable independiente "película" (visionada) se recodificó como variable dummy asignando el valor 0.5 a haber visto "Poniente" y -0.5 a haber visto "El Próximo Oriente", siguiendo las recomendaciones de Hayes (2013). La variable racismo moderno (RM) presenta un rango de puntuaciones desde 1 "valor mínimo", hasta 7 "valor máximo". En la tabla se incluyen los coeficientes $B$, que son coeficientes de regresión no estandarizados. 
Los resultados de los análisis permiten concluir que la exposición a la película Poniente indujo una mayor identificación con los personajes del exogrupo que el visionado de la película El Próximo Oriente $(B=1.16, p<.002)$ y que, a su vez, la identificación se asoció a una actitud más positiva hacia la inmigración $(B=.77, p<.001)$. Ahora bien, la existencia de un efecto de interacción estadísticamente significativo entre la película vista y el nivel de racismo moderno de los participantes $(B=-.22, p<.052)$, implica que los efectos indirectos condicionales solo eran estadísticamente significativos cuando el nivel previo de prejuicio era bajo $(B$ efecto indirecto $=.59, S E=.24$, IC $95 \%[.20,1.16])$ o moderado $(B$ efecto indirecto $=.37, S E=.16, I C 95 \%$ $[.12, .78])$.

\section{CONCLUSIONES Y DISCUSIÓN}

La investigación que se presenta constituye uno de los primeros estudios realizados en España sobre los procesos de recepción e impacto de las películas sobre inmigración y su utilidad como herramientas para fomentar cambios prosociales como la mejora de las actitudes hacia la inmigración. Los resultados de la investigación permiten concluir que la estrategia basada en fomentar la empatía parece mucho más eficaz como herramienta de intervención, en comparación con la estrategia audiovisual que muestra situaciones de contacto intergrupal positivo e íntimo (relaciones de pareja intergrupales), para fomentar una actitud favorable hacia la inmigración, lo cual es congruente con la investigación de Batson et al. (1997).

En la investigación también se ha observado que las personas que vieron la película Poniente experimentaron una mayor identificación con los personajes del exogrupo, que los participantes que vieron la película El Próximo Oriente. Además, se observó que el racismo moderno influía en la identificación con los personajes del exogrupo: a mayor racismo moderno, menor identificación con los personajes del exogrupo, resultado coherente con la hipótesis del contacto intergrupal mediático (Park, 2012). Pero el resultado más relevante es que Poniente indujo mayor identificación con los personajes del exogrupo que El Próximo Oriente, pero únicamente cuando el racismo moderno era bajo o moderado. Esto significa que 
a pesar de que la película Poniente mostraba situaciones dramáticas, con escenas claras de discriminación y de xenofobia, las reacciones de identificación empática hacia los personajes inmigrantes solo se producían en aquellas personas con un nivel bajo o medio de prejuicio hacia dicho colectivo.

La literatura sobre persuasión narrativa y la investigación sobre contacto mediático intergrupal consideran que la identificación con los personajes es un proceso o mecanismo mediador que explica el impacto actitudinal (Müller, 2009; Park, 2012). Los resultados del estudio son convergentes con estos planteamientos teóricos. Así, se observó que el visionado de la película Poniente indujo una mayor identificación con los personajes del exogrupo que el visionado de la película El Próximo Oriente, y dicho proceso a su vez se asociaba con una actitud más favorable hacia la inmigración. Ahora bien, este proceso mediador solo se produjo entre las personas que manifestaban, un nivel bajo o moderado de racismo moderno. Este resultado es relevante por varios motivos.

En primer lugar, los resultados del estudio son convergentes con los obtenidos por Müller (2009), en su investigación realizada en Países Bajos en la que se trabajó con una serie televisiva que fomentaba el contacto intercultural. Sin embargo, en dicho estudio no se analizó el papel de prejuicio previo en los procesos de recepción, elemento que sí se ha incluido en la presente investigación como innovación metodológica.

En segundo lugar, se pone de manifiesto que es más efectiva una estrategia basada en fomentar la empatía hacia los inmigrantes que mostrar, con un tono desenfadado o cómico, situaciones de contacto íntimo de carácter intergrupal. Hay que tener en cuenta que las películas dramáticas fomentan más las respuestas de tipo eudaimónico (como la reflexión, o la sensación de que la película genera una impresión duradera) que las películas con un componente menos dramático como las comedias, las cuales estimulan reacciones de disfrute de tipo hedónico, emociones positivas y provocan menos reflexión (Oliver y Bartsch; 2010; Oliver y Raney, 2011).

En tercer lugar, los resultados son convergentes con el modelo M3PI (Igartua, 2007, 2011), ya que se observa que las personas más susceptibles de ser persuadidas mediante una película de ficción como Poniente serían aquellas que manifestaran una postura más cercana hacia los inmigrantes, mostrando un nivel de prejuicio bajo o moderado. Este resultado tiene claras implicaciones prácticas: 
significa que la estrategia de intervención basada en la empatía tendría limitaciones cuando se aplica a personas con un alto prejuicio previo. Por tanto, el reto para las investigaciones del futuro es averiguar cómo mejorar las actitudes intergrupales en personas con un nivel previo de alto prejuicio, dado que son precisamente estas personas las que más necesitarían experimentar cambios en sus actitudes. Se pone de manifiesto que provocar identificación con personajes estigmatizados (como los inmigrantes en nuestro contexto) y así, indirectamente, favorecer actitudes positivas hacia el contacto intergrupal se convierte en un desafío para guionistas y creadores de contenidos de ficción (Park, 2012).

\section{REFERENCIAS}

Arana, R. (2007): La inmigración en clave de comedia. Bilbao, Bakeaz.

Batson, C. D., Polycarpou, M. P., Harmon-Jones, E., Imhoff, H. J., Mitchener, E. C., Bednar, L. L., Klein, T. R. y Highberger, L. (1997): “Empathy and attitudes: can feelings for a member of a stigmatized group improve feelings toward the group?" Journal of Personality and Social Psychology, 72(1), pp. 105-118.

Baumert, A., Hofmann, W. y Blum, G. (2008): "Laughing about Hitler? Evaluation of the movie 'My Fuehrer - The Truly Truest Truth about Adolf Hitler'. Journal of Media Psychology, 20(2), pp. 43-56.

Campbell, D. y Stanley, J. (1973): Diseños experimentales y cuasi experimentales en la investigación social. Buenos Aires, Amorrortu.

Castiello, C. (2005): Los parias de la tierra. Inmigrantes en el cine español. Madrid, Talasa.

Cea D'ancona, M. A. (2004): La activación de la xenofobia en España. ¿Qué miden las encuestas? Madrid, CIS-Siglo XXI.

Cohen, J. (2001): "Defining identification: a theoretical look at the identification of audiences with media characters". Mass Communication and Society, 4(3), pp. 245-264.

Conte, D. (2010): "Espacios discursivos de la inmigración". En M. Iglesias (Ed.), Imágenes del otro. Identidad e inmigración en la literatura y el cine (pp. 33-61). Madrid, Editorial Biblioteca Nueva.

CRISP, R. J. y TURNER, R. N. (2009): "Can imagined interactions produce positive perceptions? Reducing prejudice through simulated social contact". American Psychologist, 64(4), pp. 231-240.

Dahlstrom, M. F. (2010): "The role of causality in information acceptance in narratives: an example from science communication". Communication Research, 37(6), pp. 857-875. 
DAL Cin, S., ZANNA, M. P. y Fong, G. T. (2002): "Narrative persuasion and overcoming resistance”. En E. S. KNowles y J. A. LinN (Eds.), Resistance and persuasion (pp. 175-191). Mahwah, NJ, Lawrence Erlbaum Associates.

De Graaf, A., Hoeken, H., Sanders, J. y Beentjes, H. (2012): "Identification as a mechanism of narrative persuasion”. Communication Research, 39(6), pp. 802-823.

Diekman, A. B., McDonald, M. y Gardner, W. L. (2000): "Love means never having to be careful: The relationship between reading romance novels and safe sex behavior". Psychology of Women Quarterly, 24, pp. 179-188.

ENo, C. A. y Ewoldsen, D. (2010): "The influence of explicitly and implicitly measured prejudice on interpretations of and reactions to black film". Media Psychology, 13, pp. 1-30.

Espelt, E. (2009): ¿Somos racistas? Valores solidarios y racismo latente. Barcelona, Icaria.

Finlay, K. A y Stephan, W. G. (2000): "Improving intergroup relations: the effects of empathy on racial attitudes". Journal of Applied Social Psychology, 30(8), pp. 1720-1737.

GordiLlo, I. (2006): “El diálogo intercultural en el cine español contemporáneo: entre el estereotipo y el etnocentrismo”. Comunicación, 4, pp. 207-222.

Green, M. C. y Brock, T. C. (2000): "The role of transportation in the persuasiveness of public narratives”. Journal of Personality and Social Psychology, 79(5), pp. 701-721.

Hayes, A. F. (2009): "Beyond Baron and Kenny: statistical mediation analysis in the new millennium”. Communication Monographs, 76(4), pp. 408-420.

HaYes, A. F. (2013): Introduction to mediation, moderation and conditional process analysis.A regression-based approach. Nueva York, NY, The Guilford Press.

Hayes, A. F. y Matthes, M. (2009): “Computational procedures for probing interaction in OLS and logistic regression: SPSS and SAS implementations”. Behavior Research Methods, 41(3), pp. 924-936.

IgARTUA, J. J. (2006): Métodos cuantitativos de investigación en comunicación. Barcelona, Bosch.

- (2007): Persuasión narrativa. Alicante, Editorial Club Universitario.

- (2010): "Identification with characters and narrative persuasion through fictional feature films". Communications. The European Journal of Communication Research, 35(4), pp. 347-373.

- (2011): "Comunicación mediática, educación para la paz y persuasión narrativa”. En D. PÁez, C. Martín Beristain, J. L. González-Castro, N. BaSABE y J. DE RIVERA (Eds.), Superando la violencia colectiva y construyendo cultura de paz (pp. 631-668). Madrid, Fundamentos.

IgARTUA, J. J. y BARRIos, I. M. (2012): "Changing real-world beliefs with controversial movies. Processes and mechanisms of narrative persuasion". Journal of Communication, 62(3), pp. 514-531.

Iglesias, M. (2010) (Ed.): Imágenes del otro. Identidad e inmigración en la literatura y el cine. Madrid, Editorial Biblioteca Nueva. 
Martínez-Carazo, C. (2010): "Inmigración en el cine español. El otro que es siempre el mismo”. En M. Iglesias (Ed.), Imágenes del otro. Identidad e inmigración en la literatura y el cine (pp. 185-197). Madrid, Editorial Biblioteca Nueva.

McConahay, J. B., Hardee, B. B. y Batts, V. (1981): "Has racism declined in America? It depends upon who is asking and what is asked". Journal of Conflict Resolution, 25, pp. 563-579.

Molero, F. (2007): "El estudio del prejuicio en la psicología social: definición y causas”. En J. F. Morales, M. C. Moya, E. Gaviria e I. Cuadrado (Coords.), Psicología social (pp. 591-617). Madrid, McGraw-Hill (3ª edición).

Moyer-Gusé, E. (2008): “Toward a theory of entertainment persuasion: explaining the persuasive effects of entertainment-education messages". Communication Theory, 18(3), pp. 407-425.

Moyer-Gusé, E. y NABI, R. L. (2010): "Explaining the effects of narrative in an entertainment television program: overcoming resistance to persuasion”. Human Communication Research, 36(1), pp. 26-52.

Moyano, E. (2005): La memoria escondida. Emigración y cine. Madrid, Tabla Rasa.

Müller, F. (2009): “Entertainment anti-racism. Multicultural television drama, identification and perceptions of ethnic threat". Communications. European Journal of Communication Research, 34(3), pp. 239-256.

Navas, M. S. (1998): "Nuevos instrumentos de medida para el nuevo racismo”. Revista de Psicología Social, 13(2), pp. 233-239.

Oliver, M. B. y Bartsch, A. (2010): "Appreciation as audience response. Exploring entertainment gratifications beyond hedonism”. Human Communication Research, 36(1), pp. 53-81.

Oliver, M. B. y Raney, A. A. (2011): “Entertainment as pleasurable and meaningful: identifying hedonic and eudaimonic motivations for entertainment consumption”. Journal of Communication, 61, pp. 984-1004.

Páez, D., Bobowik, M., Carrera, P. y Bosco, S. (2012): “Anexo al capítulo 4. Evaluación de la afectividad durante diferentes episodios emocionales”. En D. Páez, C. Martín Beristain, J. L. González-Castro, N. Basabe y J. de RIVERA (Eds.), Superando la violencia colectiva y construyendo cultura de paz (pp. 151-161). Madrid: Fundamentos.

PARK, S. Y. (2012): "Mediated intergroup contact: concept explication, synthesis, and application”. Mass Communication and Society, 15(1), pp. 136-159.

Pettigrew, T. F. y Tropp, L. R. (2006): “A meta-analytic test of intergroup contact theory”. Journal of Personality and Social Psychology, 90(5), pp. 751-783.

Santaolalla, I. (2005): Los 'otros'. Etnicidad y raza en el cine español contemporáneo. Zaragoza, Prensas Universitarias.

Schiappa, E., GregG, P. B. y Hewes, D. E. (2005): “The parasocial contact hypothesis”. Communication Monographs, 72, pp. 92-115. 
Sherif, M. y Hovland, C. I. (1961): Social judgment. Assimilation and contrast effects in communications and attitude change. New Haven, CT, Yale University Press.

Slater, M. D. y Rouner, D. (2002): "Entertainment-education and elaboration likelihood: understanding the processing of narrative persuasion". Communication Theory, 12(2), pp. 173-191.

Slater, M. D. y Rouner, D. y Long, M. (2006): “Television dramas and support for controversial public policies: effects and mechanisms". Journal of Communication, 56(2), pp. 235-252.

TAJfel, H. (1982): Social identity and intergroup relations. Cambridge, Cambridge University Press.

Wright, S. C., Aron, A., Mclaughlin-Volpe, T. y Ropp, S. A. (1997): “The extended contact effect: knowledge of cross-group friendships and prejudice". Journal of Personality and Social Psychology, 73(1), pp. 73-90.

Zессні, B. (2010): "Veinte años de inmigración en el imaginario fílmico español”. En M. Iglesias (Ed.), Imágenes del otro. Identidad e inmigración en la literatura y el cine (pp. 157-184). Madrid, Editorial Biblioteca Nueva. 